\title{
Hydroxyl radical-aided thermal pretreatment of algal biomass for enhanced biodegradability
}

\author{
Le Gao, Demao Li, Feng Gao, Zhiyong Liu, Yuyong Hou, Shulin Chen and Dongyuan Zhang*
}

\begin{abstract}
Background: Algal biomass, known as a potential feedstock for biofuel production, has cell wall structures that differ from terrestrial biomass. The existing methods for processing algae are limited to conventional pretreatments for terrestrial biomass.

Results: In this study, we investigated a novel hydroxyl radical-aided approach for pretreating different types of algal biomass. In this process, hydroxyl radicals formed by a Fenton system were employed in combination with heating to alter the crystalline structure and hydrogen bonds of cellulose in the algal biomass. $\mathrm{FeSO}_{4}$ and $\mathrm{H}_{2} \mathrm{O}_{2}$ at low concentrations were employed to initiate the formation of hydroxyl radicals. This method releases trapped polysaccharides in algal cell walls and converts them into fermentable sugars. The effects of temperature, time, and hydroxyl radical concentration were analyzed. The optimal pretreatment condition $\left[100{ }^{\circ} \mathrm{C}, 30\right.$ min, and $5.3 \mathrm{mM} \mathrm{H}_{2} \mathrm{O}_{2}$ (determined $\mathrm{FeSO}_{4}$ concentration of $11.9 \mathrm{mM}$ )] was identified using a central composite design. Complete (100\%) carbohydrate recovery was achieved with some algal biomass without formation of inhibitors such as hydroxymethylfurfural and furfural as by-products. Both microalgal and macroalgal biomasses showed higher enzymatic digestibility of cellulose conversion (>80 \%) after the milder pretreatment condition.
\end{abstract}

Conclusion: Hydroxyl radical-aided thermal pretreatment was used as a novel method to convert the carbohydrates in the algal cell wall into simple sugars. Overall, this method increased the amount of glucose released from the algal biomass. Overall, enhanced algal biomass digestibility was demonstrated with the proposed pretreatment process. The new pretreatment requires low concentration of chemical solvents and milder temperature conditions, which can prevent the toxic and corrosive effects that typically result from conventional pretreatments. Our data showed that the advantages of the new pretreatment include higher carbohydrate recovery, no inhibitor production, and lower energy consumption. The new pretreatment development mimicking natural system could be useful for biochemical conversion of algal biomass to fuels and chemicals.

Keywords: Pretreatment, Hydroxyl radical-aided thermal pretreatment, Algal biomass, Hydroxyl radicals, Fenton system

\section{Background}

Algal biomass, known as a "third-generation biomass feedstock" for biofuel production, has received considerable attention because of its high productivity, negligible

\footnotetext{
*Correspondence: Zhang_dy@tib.cas.cn

Tianjin Key Laboratory for Industrial BioSystems and Bioprocessing Engineering, Tianjin Institute of Industrial Biotechnology, Chinese Academy of Sciences, No. 32, Xiqi Road, Tianjin Airport Economic Park, Tianjin 300308, China
}

lignin content, and high $\mathrm{CO}_{2}$ mitigation effects compared with terrestrial biomass [1]. Algal biomass processing for biofuel production also has other advantages such as low lignin and hemicellulose concentrations compared with other lignocellulosic plants [2]. Compared with land plants, algae have different cell wall layers with different chemical compositions but lack an overall generic structure. Algal cell walls are thin, and their primary and secondary cell walls are undivided [3]. An 
algal cell wall without lignin has a relatively loose structure, which is different from other plant cell walls. The hydrolysis of algae to produce fermentable sugars aside from high-value products, however, often hinders the comprehensive utilization of algae. The algae pretreatment is regarded as an important step to facilitate the release of the sugars [4]. The pretreatments for algal biomass are typically performed under extreme conditions: high temperatures of $120-220{ }^{\circ} \mathrm{C}$, and high concentration of chemical solvents to increase relative content cellulose, which still followed the traditional pretreatment methods for terrestrial biomass. There have been many reports about algal pretreatments. The marine macroalga Nizimuddinia zanardini was subjected to 7 \% dilute sulfuric acid pretreatments at $121{ }^{\circ} \mathrm{C}$ for $45 \mathrm{~min}$, and the cellulose conversion of macroalgae was only $31.8 \%$ [5]. An acid pretreatment using $0.06 \%(\mathrm{w} / \mathrm{w})$ sulfuric acid at $170{ }^{\circ} \mathrm{C}$ for $15 \mathrm{~min}$ was employed to Saccharina japonica, brown macroalgae. The cellulose conversion of macroaglae reached $83.37 \%$ [6]. Numerous inhibitors, such as hydroxymethylfurfural (HMF), 2-furfural, and acetic acid, were also formed in hydrothermal pretreatment at $200{ }^{\circ} \mathrm{C}$, wet oxidation pretreatment using 12 bars of $\mathrm{O}_{2}$ at $200{ }^{\circ} \mathrm{C}$, and steam explosion pretreatment [7], besides acid or alkali pretreatment for algal biomass. These inhibitors may affect the downstream production of highvalue algae products. A neutralization process is required for enzymatic hydrolysis after dilute acid pretreatment. Current algae pretreatments are very expensive because of their high-temperature and high-energy requirements. A new pretreatment technology is urgently needed for algal comprehensive utilization with low cost and low energy.

In nature, the wood-decaying microorganisms and wood-feeding termites are able to digest lignocellulosic substrates efficiently using hydroxyl radicals [8]. The lignocellulosic-preconditioning system used hydroxyl radicals to depolymerize lignocellulose under mild environmental conditions. A well-known process that produces radicals is Fenton's reaction in which hydroxyl radicals $(\cdot \mathrm{OH})$ are produced in the solution through the reaction of $\mathrm{Fe}^{2+}$ ions with $\mathrm{H}_{2} \mathrm{O}_{2}$. Using Fenton reaction, hydroxyl radicals formation was simulated and amplified in vitro. There has been report on use of $\cdot \mathrm{OH}$ to pretreat lignocellulosic biomass [9]. According to Gould [10], lignocellulosic biomass requires a long pretreatment time, relatively harsh conditions, and a high $\cdot \mathrm{OH}$ concentration because of the relatively tight structure of lignocellulose.

$\mathrm{Fe}^{2+}+\mathrm{H}_{2} \mathrm{O}_{2} \rightarrow \mathrm{Fe}^{3+}+\mathrm{OH}^{-}+\cdot \mathrm{OH}$ (Fenton's reaction)

For the unique structural features of algal biomass, this study investigated a new pretreatment based on hydroxyl radicals' effects of processing under the milder reaction conditions and low concentrations of chemical reagents. The present study investigated the effects of processing variables, including hydroxyl radical concentration, pretreatment time, and pretreatment temperature, on the glucose production of different types of algal biomass. Moreover, the present study explored good applicability of the new pretreatment for different algal biomasses containing four macroalgae (Macrocystis pyrifera, Ulva prolifera, Gelidium amansii, and Porphyra umbilicalis) and four microalgae (Chlorella sorokiniana, Scenedesmus quadricanda, Haematococcus pluvialis, and Chlamydomonas hedleyi). The hydroxyl radical-aided thermal pretreatment achieved complete (100\%) carbohydrate recovery of algal biomass and substantially improved algal biomass digestibility. There were no inhibitors produced in this pretreatment process. This new pretreatment is a low-cost, high-recovery, and environmentally friendly pretreatment method, which could combine with other high-value materials' extraction from algal biomass to achieve the complete utilization of alga.

\section{Results and discussion \\ Algal biomass content}

The constituents of the algal biomass significantly differed from those of terrestrial biomass and also varied with species. The principal components of algal cell wall are listed in Table 1. Green algae contained the highest lignocellulose content. The total amounts of cellulose and hemicellulose in $U$. prolifera, C. sorokiniana,

Table 1 Experimental design matrix for the optimization of pretreatment conditions

\begin{tabular}{llllll}
\hline Run & Tri no. & Tri no. & $\begin{array}{l}\text { Temperature } \\
\left({ }^{\circ} \mathbf{C}\right)\end{array}$ & $\begin{array}{l}\text { Time } \\
(\mathbf{m i n})\end{array}$ & $\begin{array}{l}\mathbf{H}_{\mathbf{2}} \mathbf{O}_{\mathbf{2}} \\
\text { (oncentration } \\
(\mathbf{m M})\end{array}$ \\
\hline 1 & $\mathrm{J1}^{\mathrm{a}}$ & $\mathrm{H} 1^{\mathrm{b}}$ & 80 & 30 & 7.1 \\
2 & $\mathrm{~J} 2$ & $\mathrm{H} 2$ & 120 & 15 & 5.3 \\
3 & $\mathrm{~J} 3$ & $\mathrm{H} 3$ & 120 & 30 & 7.1 \\
4 & $\mathrm{J4}$ & $\mathrm{H} 4$ & 100 & 15 & 7.1 \\
5 & $\mathrm{~J} 5$ & $\mathrm{H} 5$ & 100 & 45 & 7.1 \\
6 & $\mathrm{~J} 6$ & $\mathrm{H} 6$ & 80 & 30 & 3.5 \\
7 & $\mathrm{~J} 7$ & $\mathrm{H} 7$ & 100 & 30 & 5.3 \\
8 & $\mathrm{~J} 8$ & $\mathrm{H} 8$ & 120 & 30 & 3.5 \\
9 & $\mathrm{J9}$ & $\mathrm{H} 9$ & 100 & 30 & 5.3 \\
10 & $\mathrm{~J} 10$ & $\mathrm{H} 10$ & 100 & 15 & 3.5 \\
11 & $\mathrm{J11}$ & $\mathrm{H} 11$ & 100 & 45 & 3.5 \\
12 & $\mathrm{J12}$ & $\mathrm{H} 12$ & 80 & 15 & 5.3 \\
13 & $\mathrm{~J} 13$ & $\mathrm{H} 13$ & 100 & 30 & 5.3 \\
14 & $\mathrm{~J} 14$ & $\mathrm{H} 14$ & 80 & 45 & 5.3 \\
15 & $\mathrm{J15}$ & $\mathrm{H} 15$ & 120 & 45 & 5.3 \\
\hline
\end{tabular}

a Macrocystis pyrifera

b Ulva prolifera 
S. quadricanda, $H$. pluvialis, and C. hedleyi were 18.81, $22.69,16.86,30.97$, and $20.12 \%$, respectively. The cellulose content in green algal biomass was higher than that in red and brown algal biomasses. Cellulose is a partially crystalline skeletal component that provides strength. The liquid contents of the microalgal biomass from $C$. sorokiniana, $S$. quadricanda, and C. hedleyi were similar. The biomass from red algae, unlike those from the other algae, had higher hemicellulose content and lower ash content. The hemicellulose contents in red algal biomass, including $47.16 \%$ in P. umbilicalis and $24.37 \%$ in G. amansii, were higher than those in the other biomass. The ash contents in C. sorokiniana and H. pluvialis were approximately 3.79 and $3.93 \%$, respectively, each of which was one tenth of the ash content in brown macroalgae. High ash content is not conducive to the effect of pretreatment because it causes slagging and fouling problems during thermochemical conversion [11]. The principal polysaccharides in brown algae are alginates, laminarin, and mannitol [12], whereas those in red algae are agar and carrageenan [13]. The biodegradability of each component has not been fully investigated. Besides the high-value products from algal biomass, the algal cell contains significant quantities of carbohydrates, which may be used to produce glucose for biofuels. In this connection, choosing the correct method for algal biomass pretreatment is obviously important, since it affects the enzymatic digestibility of algal biomass. At the next stage of this work, the pretreatment condition of algal biomass would be evaluated.

\section{Effect of pretreatment conditions on enzymatic hydrolysis}

Table 2 presents the effects of hydroxyl radical-aided thermal pretreatment on the glucose yield of different types of algal biomass, including $M$. pyrifera and $U$. prolifera, under different reaction times, temperatures, and $\mathrm{H}_{2} \mathrm{O}_{2}$ concentrations. The optimal pretreatment conditions for M. pyrifera and U. prolifera were $100{ }^{\circ} \mathrm{C}, 30 \mathrm{~min}$, and $5.3 \mathrm{mM} \mathrm{H}_{2} \mathrm{O}_{2}$ (Trial Nos. 7, 9, and 13 in Table 2). The glucose yields from $M$. pyrifera and $U$. prolifera were 64.63 and $143.19 \mathrm{mg} / \mathrm{g}$ dry matter (DM) (average of J7, J9, J13), respectively (Figs. 1, 2). The cellulose conversions in

Table 2 Proximate analysis of dried algal biomass

\begin{tabular}{|c|c|c|c|c|c|c|c|c|}
\hline & \multicolumn{4}{|l|}{ Microalgae } & \multicolumn{4}{|l|}{ Macroalgae } \\
\hline & $\begin{array}{l}\text { Chlorella } \\
\text { sorokiniana }\end{array}$ & $\begin{array}{l}\text { Scenedesmus } \\
\text { quadricanda }\end{array}$ & $\begin{array}{l}\text { Haematococ- } \\
\text { cus pluvialis }\end{array}$ & $\begin{array}{l}\text { Chla- } \\
\text { mydomonas } \\
\text { hedleyi }\end{array}$ & Ulva prolifera & $\begin{array}{l}\text { Porphyra } \\
\text { umbilicalis }\end{array}$ & $\begin{array}{l}\text { Gelidium } \\
\text { amansii }\end{array}$ & $\begin{array}{l}\text { Macrocystis } \\
\text { pyrifera }\end{array}$ \\
\hline Cellulose (\%) & $17.69 \pm 0.078$ & $16.04 \pm 0.032$ & $16.55 \pm 0.048$ & $18.67 \pm 0.041$ & $15.20 \pm 0.024$ & $9.84 \pm 0.011$ & $9.09 \pm 0.013$ & $5.90 \pm 0.010$ \\
\hline $\begin{array}{l}\text { Hemicellulose } \\
\text { (\%) }\end{array}$ & $4.99 \pm 0.014$ & $0.82 \pm 0.049$ & $14.42 \pm 0.034$ & $1.45 \pm 0.012$ & $3.61 \pm 0.014$ & $47.16 \pm 0.057$ & $24.37 \pm 0.044$ & $0.91 \pm 0.010$ \\
\hline Ash (\%) & $3.79 \pm 0.017$ & $21.25 \pm 0.042$ & $3.93 \pm 0.012$ & $30.27 \pm 0.047$ & $26.10 \pm 0.033$ & $6.77 \pm 0.012$ & $4.89 \pm 0.012$ & $35.2 \pm 0.057$ \\
\hline Crude fat (\%) & $23.74 \pm 0.024$ & $23.10 \pm 0.041$ & $11.25 \pm 0.048$ & $24.75 \pm 0.041$ & $3.70 \pm 0.011$ & $9.75 \pm 0.022$ & $7.75 \pm 0.013$ & $4.33 \pm 0.011$ \\
\hline Protein (\%) & $2.74 \pm 0.011$ & $2.23 \pm 0.012$ & $3.56 \pm 0.016$ & $1.66 \pm 0.012$ & $2.70 \pm 0.017$ & $1.83 \pm 0.018$ & $2.80 \pm 0.015$ & $0.29 \pm 0.001$ \\
\hline Others (\%) & $47.05 \pm 0.047$ & $36.56 \pm 0.043$ & $50.29 \pm 0.054$ & $23.20 \pm 0.022$ & $48.69 \pm 0.041$ & $24.65 \pm 0.057$ & $51.10 \pm 0.057$ & $53.37 \pm 0.049$ \\
\hline
\end{tabular}
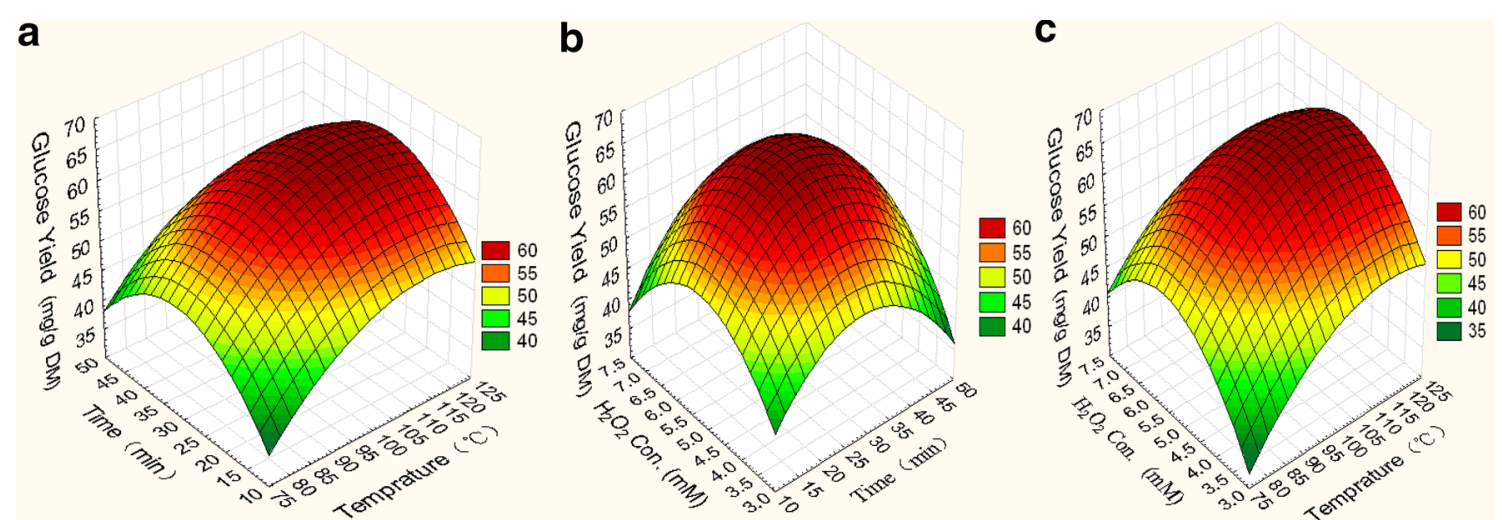

Fig. 1 Response surface curve representing the interactive effects of temperature, time, and FeSO ${ }_{4}$ concentration on the digestibility of Macrocystis pyrifera: a effects of temperature and time; $\mathbf{b}$ effects of temperature and $\mathrm{H}_{2} \mathrm{O}_{2}$ concentration; and $\mathbf{c}$ effects of time and $\mathrm{H}_{2} \mathrm{O}_{2}$ concentration 
a

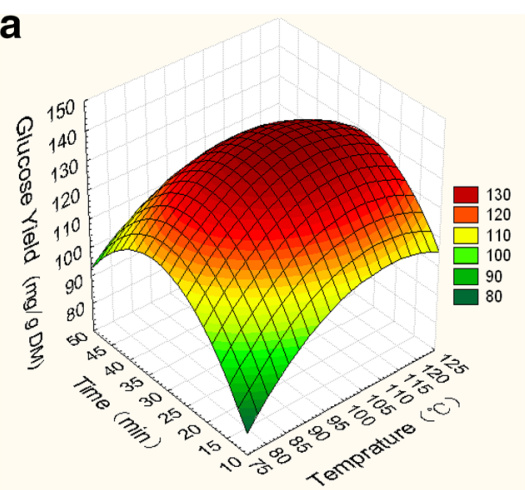

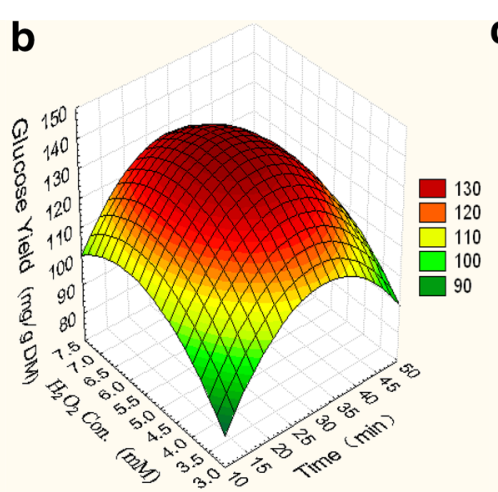

C

Fig. 2 Response surface curve representing the interactive effects of temperature, time, and $\mathrm{FeSO}_{4}$ concentration on the digestibility of $U$. prolifera: a effects of temperature and time; $\mathbf{b}$ effects of temperature and $\mathrm{H}_{2} \mathrm{O}_{2}$ concentration; and $\mathbf{c}$ effects of time and $\mathrm{H}_{2} \mathrm{O}_{2}$ concentration

M. pyrifera and $U$. prolifera reached 98.59 and $84.79 \%$, respectively, which were higher than those obtained using conventional pretreatment methods [14]. Meanwhile, under $1 \%$ alkali or $1 \%$ acid pretreatment for $60 \mathrm{~min}$, the M. pyrifera cellulose digestibility only reached 62.2 and $54.1 \%$, respectively. The glucose yields from macroalgae that were pretreated with $0.5,3.5$, and $7 \%$ dilute sulfuric acid at $120{ }^{\circ} \mathrm{C}$ and then subjected to commercial cellulose conversion are $16,19,31.8 \%$, respectively [14]. The cellulose conversion of the brown macroalga Sargassum sp. reached $21.6 \%$ after treatment with $5 \% \mathrm{H}_{2} \mathrm{SO}_{4}$ at $115{ }^{\circ} \mathrm{C}$ for $90 \mathrm{~min}$ and then hydrolysis using a high load of commercial cellulase (50 FPU/g of biomass) [14]. The M. pyrifera cellulose digestibility reached $92.1 \%$ under integrated hydroxyl radicals and hot water (HW) pretreatment which needs two-step process with an HW pretreatment as step I and an HR pretreatment by Fenton reaction as step II [15]. The hydroxyl radical-aided thermal pretreatment in this study integrated two steps of previous pretreatment to form a simple technology and used a high temperature of hot water pretreatment to accelerate the motion of hydroxyl radicals, which had better effect on enhancing algal biomass than the previous pretreatment.

Less or more stringent pretreatment conditions resulted in low conversion ratios of cellulose. As shown in Table 1 , temperatures up to $120^{\circ} \mathrm{C}$ produced low glucose yields, which were also observed in other pretreatment methods. Grohman et al. [16]. reported that acid pretreatment temperatures between 140 and $160{ }^{\circ} \mathrm{C}$ produce highly digestible cellulose from aspen and straw biomasses. High acid pretreatment temperatures up to $180{ }^{\circ} \mathrm{C}$ significantly decrease the amount of released fermentable sugars. Many studies suggested that $140{ }^{\circ} \mathrm{C}$ is the most suitable acid pretreatment temperature [17]. Hydroxyl radical-aided thermal pretreatment, which requires a temperature of $100{ }^{\circ} \mathrm{C}$ for $30 \mathrm{~min}$, is milder than conventional pretreatments. Therefore, the pretreatment used in this study is more energy efficient.

The pretreatment method used in the present study requires lower concentrations of chemical solvents than acid or alkali pretreatment. The costs of concentrated acid for the dilute acid pretreatment, $\mathrm{O}_{2}$ for the wet oxidation pretreatment, energy consumption in the steam pretreatment, and solvents in the organic solvent pretreatment were too expensive compared with the value of glucose [15]. The lower processing temperature, fewer chemicals, and enzyme dosage of the new pretreatment indicate that it is likely to cost less than conventional methods. The material cost of the new pretreatment was 13.17 US dollars/ton biomass, which contained the cost of ferrous sulfate, hydrogen peroxide, and water. The low-pressure steam cost of new pretreatment was 9.35 US dollars/ton biomass. The cost of this new pretreatment for one ton of algal biomasses was 22.52 US dollars/ ton biomass, which is $1 / 3$ of the traditional pretreatment cost. The new pretreatment does not need corrosive liquid and a neutralization process, which could reduce equipment requirement and equipment depreciation.

\section{Applicability of hydroxyl radical-aided thermal pretreatment for different types of algal biomass}

As shown in Fig. 3, eight types of algal biomasses, including four from microalgae and four from macroalgae, were processed under the optimal experimental conditions of $100{ }^{\circ} \mathrm{C}, 30 \mathrm{~min}$, and $5.3 \mathrm{mM} \mathrm{H} \mathrm{H}_{2}$. The untreated and treated algal biomasses were compared by enzymolysis experiment to analyze algal digestibility change. The glucose yields of the microalgae C. sorokiniana, S. quadricanda, $H$. pluvialis, and $C$. hedleyi after saccharification were 152.07, 136.45, 146.43, and $136.65 \mathrm{mg} / \mathrm{g} \mathrm{DM}$, respectively, which were equivalent to approximately 


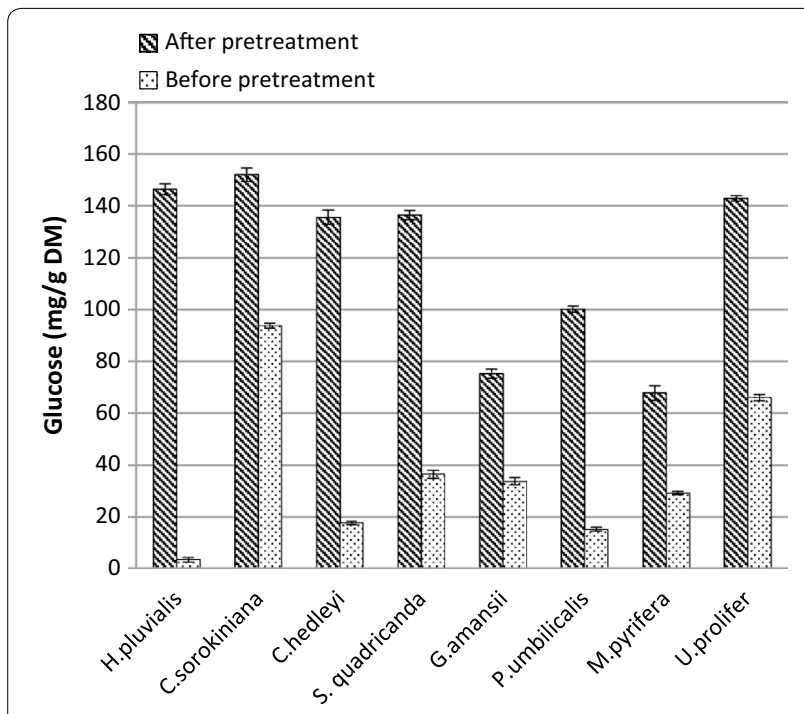

Fig. 3 Comparison of the enzymatic digestibility of algal biomass before and after thermal hydroxyl radical pretreatment

$80 \%$ algal cellulose conversion. The values were approximately 0.62-, 2.72-, 39.64-, and 6.67-fold higher, respectively, than that from untreated algal biomass. The effect of this pretreatment was better on macroalgae than on microalgae. The glucose yields of the macroalgae G. amansii, $P$. umbilicalis, $M$. pyrifera, and $U$. prolifera were $75.24,100.20,67.80$, and $142.87 \mathrm{mg} / \mathrm{g} \mathrm{DM}$, respectively. The cellulose conversion of macroalgae reached 84-98.59\%.

An exponential correlation was observed between the cellulose content of untreated algal biomass and treated algal biodegradability (Fig. 4). The algal species with

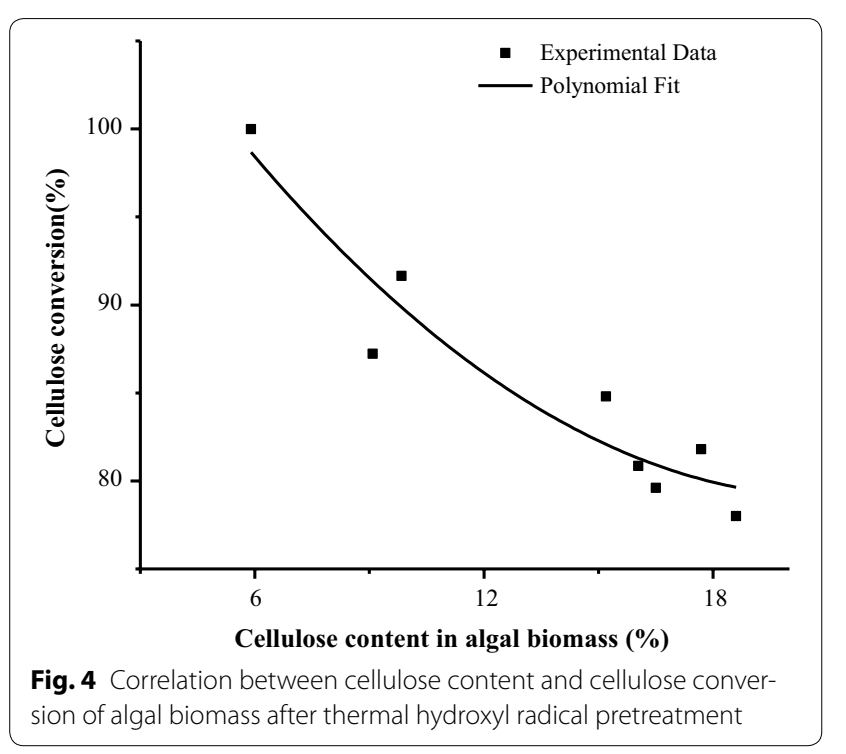

high cellulose contents showed lower cellulose conversion than those with low cellulose contents. When the cellulose content in the algal biomass was lower than $20 \%$, the cellulose conversion rate can exceed $80 \%$. In general, algal biomass contains lower cellulose content $(<20 \%)$ than terrestrial biomass. Algal biomass with no lignin has relatively loose structure. The hydroxyl radicalaided thermal pretreatment uses hydroxyl radicals participating in the crystalline structural and hydrogen-bond disruptions. The milder reaction had no effect on highvalue substances' extraction and carbohydrate recovery. Therefore, the hydroxyl radical-aided thermal pretreatment is suitable for improving algal biomass digestibility. Terrestrial biomass usually has more than $30 \%$ cellulose content and large amounts of hemicellulose and lignin, which are bound together in a complex structure. The ultrastructure of cellulose is compact due to the presence of covalent bonds, hydrogen bonding, and van der Waals forces. Due to the low concentration of hydroxyl radicals and short reaction time, the terrestrial biomass under this pretreatment condition does not have good saccharification results like algal biomass. For the terrestrial biomass with compact structure, this new pretreatment can be improved through extending the pretreatment time and increasing the hydroxyl radicals' concentration.

Microalgal cells have abundant proteins, intracellular organic components, lipids, and other carbon-based compounds, which can easily leach during pretreatment. Therefore, microalgal biomass requires lower pretreatment conditions than macroalgal biomass [17]. However, different results were observed in the present study. The macroalgae under the same pretreatment conditions were more easily degraded than the microalgae. The microalgae had high contents of cellulose and hemicelluloses. These skeletal components are partially crystalline and are similar to the hemicelluloses of terrestrial plants [21, 22]. Macroalgae with lower cellulose content and looser structures need relatively milder pretreatment than microalgae. Therefore, the macroalgae had a higher cellulose digestibility than microalgae under similar conditions.

\section{Carbohydrate recovery of algal biomass after the novel pretreatment}

Glucose and xylose were not detected in the liquid fraction, indicating that most sugars remained in the solid fraction after the pretreatment. Analysis of the eight types of algal biomasses revealed no changes in their chemical compositions compared to those before the pretreatment (Additional file 1: Table S1). This finding agrees with the earlier observation that no sugars were detected in the liquid fraction. The carbohydrate recovery of the eight types of algal biomasses reached $100 \%$, which was higher 
than those obtained under acid, hydrothermal, wet oxidation, and steam explosion pretreatments [7]. There has been a previous report that acid, hydrothermal, wet oxidation, and steam explosion pretreatments employed to algal biomass resulted in carbohydrate losses of about 24 , 30,50 , and $31 \mathrm{~g} / 100 \mathrm{~g} \mathrm{DM}$, respectively [7].

\section{Inhibitor analysis}

Furfural and 5-HMF were not obtained from the eight types of algal biomass after the new pretreatment. This result suggests that the pretreatment in the present study is more suitable for algal biomass than conventional pretreatments. The lack of inhibitor formation coincides with the $100 \%$ carbohydrate recovery, indicating that C6 and C5 sugars were not converted into inhibitors. The algal biomass after this pretreatment can be fermented to sugar or other high-value products.

Furfural and 5-HMF, which inhibit microbial metabolism, were observed after the conventional pretreatment. Furfural, 5-HMF, and acetic acid are formed from glucose and xylose under severe pretreatment conditions [18]. Furfural concentration increasess, while glucose and xylose concentrations decrease at pretreatment temperatures higher than $170{ }^{\circ} \mathrm{C}$ [18]. Hydrothermal and wet oxidation pretreatments of macroalgae yielded high concentrations of formic acid $(0.7$ and $1.8 \mathrm{~g} / 100 \mathrm{~g}$ DM, respectively) and acetic acid $(0.2 \mathrm{~g} / 100 \mathrm{~g}$ and $1.0 \mathrm{~g} / 100 \mathrm{~g}$ DM, respectively). A high amount of furfural $(0.2 \mathrm{~g} / 100 \mathrm{~g}$ DM) can be obtained after acid and hydrothermal pretreatments [11]. High amounts of furfural and formic acid can be formed through pretreatment with $7 \%$ acid or at a high temperature (i.e., $180{ }^{\circ} \mathrm{C}$ ) $[6,19]$.

\section{Structural changes in algal biomass using Fourier-transform infrared (FTIR) spectroscopy and X-ray diffraction (XRD) analysis}

FTIR and XRD analyses were conducted to determine the structural changes after the hydroxyl radical-aided thermal pretreatment (Table 3). The broad and strong absorbance within $4000-2995 \mathrm{~cm}^{-1}$ indicated the presence of hydrogen-bonded $\mathrm{OH}$. The transmittance of the algal biomass after the pretreatment evidently increased, implying a decrease in the absorbance. The hydrogenbond intensity (HBI) was calculated from the FTIR results. The hydroxyl radical-aided thermal pretreatment applied to the microalgae and macroalgae decreased the HBIs by $38.7-94.4$ and $21.7-51.3 \%$, respectively. Simultaneously, the crystalline intensity (CrI) of the microalgae decreased by $30.8-81.0 \%$. However, the decrease in the crystalline intensity $(\mathrm{CrI})$ of the macroalgae differed per species. The crystalline intensities of $U$. prolifera and $M$. pyrifera were both approximately $26 \%$. The crystalline intensity of $P$. umbilicalis slightly changed, whereas
Table 3 Glucose concentration released from Macrocystis pyrifera and Ulva prolifera under different conditions

\begin{tabular}{|c|c|c|c|}
\hline Tri no. & $\begin{array}{l}\text { Glucose released } \\
\text { (mg/g DM) }\end{array}$ & Tri no. & $\begin{array}{l}\text { Glucose released } \\
\text { (mg/g DM) }\end{array}$ \\
\hline J1 & $46.70 \pm 0.044$ & $\mathrm{H} 1$ & $117.67 \pm 0.079$ \\
\hline$J 2$ & $56.95 \pm 0.042$ & $\mathrm{H} 2$ & $124.76 \pm 0.082$ \\
\hline$J 3$ & $58.09 \pm 0.051$ & $\mathrm{H} 3$ & $132.76 \pm 0.067$ \\
\hline$J 4$ & $54.67 \pm 0.032$ & $\mathrm{H} 4$ & $120.55 \pm 0.043$ \\
\hline$J 5$ & $54.67 \pm 0.031$ & $\mathrm{H} 5$ & $122.73 \pm 0.045$ \\
\hline J6 & $47.84 \pm 0.027$ & $\mathrm{H} 6$ & $109.30 \pm 0.035$ \\
\hline$J 7$ & $64.06 \pm 0.061$ & $\mathrm{H} 7$ & $143.99 \pm 0.047$ \\
\hline J8 & $62.64 \pm 0.064$ & $\mathrm{H} 8$ & $124.39 \pm 0.068$ \\
\hline J9 & $65.34 \pm 0.057$ & $\mathrm{H} 9$ & $142.16 \pm 0.064$ \\
\hline $\mathrm{J10}$ & $51.25 \pm 0.044$ & $\mathrm{H} 10$ & $105.34 \pm 0.057$ \\
\hline$J 11$ & $45.56 \pm 0.024$ & $\mathrm{H} 11$ & $113.51 \pm 0.078$ \\
\hline $\mathrm{J} 12$ & $47.84 \pm 0.027$ & $\mathrm{H} 12$ & $107.21 \pm 0.057$ \\
\hline$J 13$ & $64.50 \pm 0.052$ & $\mathrm{H} 13$ & $143.19 \pm 0.045$ \\
\hline $\mathrm{J} 14$ & $53.53 \pm 0.042$ & $\mathrm{H} 14$ & $114.04 \pm 0.041$ \\
\hline$J 15$ & $61.50 \pm 0.046$ & $\mathrm{H} 15$ & $118.46 \pm 0.049$ \\
\hline Control & $29.30 \pm 0.038$ & Control & $66.06 \pm 0.027$ \\
\hline
\end{tabular}

that of G. amansii decreased by $100 \%$. This result can be attributed to the variations in the composition of macroalgal biomass. However, the treated algal biomass had a higher digestibility than the untreated algal biomass. This finding coincides with the decreases in CrI and HBI in the algae.

\section{Mechanism of thermal hydroxyl radical-aided pretreatment}

The highly effective action of the hydroxyl radicals in the newly developed process can be attributed to the abundant $\mathrm{OH}$ group in the polysaccharides of algal cell walls [20]. The hydrogen-bond network in algal cellulose is the bottleneck of algae enzymolysis. The improvement in algal biomass biodegradability after the hydroxyl radical-aided thermal pretreatment suggests that the pretreatment effectively deconstructed the algal cellulose hydrogen-bond network and crystalline structure. Therefore, this process can improve algal utilization.

Most carbohydrates in algae are incorporated within the cell wall [3]. Thus, cell wall disruption is required to release the available carbohydrates and to enable an effective saccharification. The hydroxyl radical-aided thermal pretreatment conducted in this study disrupted different algal cell walls under different concentrations of hydroxyl radicals. Microscopic pictures of the microalgae cells ( $H$. pluvialis; $C$. hedleyi; $C$. sorokiniana as an example) before and after the hydroxyl radicals' pretreatment process are shown in Fig. 5 . The image before pretreatment shows the cells are clumped together, intact, 


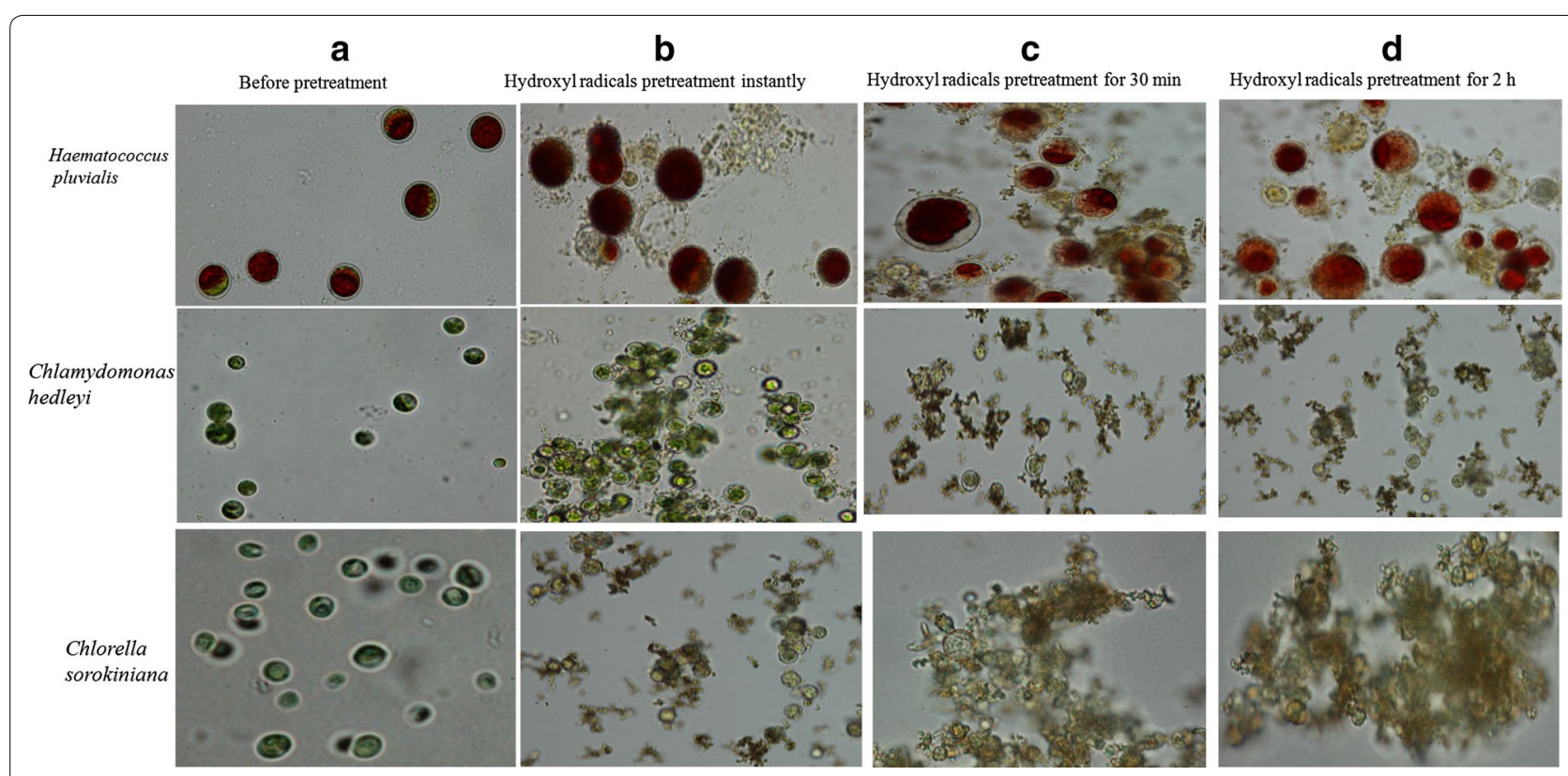

Fig. 5 The microscopic images of a microalgae before pretreatment; $\mathbf{b}$ microalgae treated by hydroxyl radicals pretreatment instantly; $\mathbf{c}$ microalgae treated by hydroxyl radicals pretreatment for $30 \mathrm{~min}$; $\mathbf{d}$ microalgae treated by hydroxyl radicals pretreatment for $2 \mathrm{~h}$

and mostly spherical in shape. One the other hand, the microscopic image of the treated microalgae by hydroxyl radicals' pretreatment instantly shows the edges of microalgae become blurred and the ruptured cell wall as evidenced by the broken cells. The microscopic image of the treated microalgae by hydroxyl radicals pretreatment for $2 \mathrm{~h}$ shows large cell debris mostly disappeared and a large number of small particles are present. The change from intact cells to broken cells after hydroxyl radicals' pretreatment confirms the effect of the novel pretreatment in the disruption of microalgae cell wall.

The constituents of biopolymers in the algal biomass significantly differed from those of terrestrial biomass and also varied with algal species. The major polysaccharides in green algae are xyloarabinogalactans, such as xylans and mannans, which serve as partially crystalline skeletal components similar to the hemicelluloses of land plants and provide additional strength [21, 22]. These structural features possibly cause the difficult degradation of green algae. The cell walls of brown and red algae contain two layers, including an inner layer of cellulose and an outer layer of gelatinous substance. Brown algae contain alginates, laminarin, and mannitol as their principal polysaccharides in the outer layer, whereas red algae possess agar and carrageenan as their principal polysaccharides. The biopolymers from the different types of algal biomass after the hydroxyl radical-aided thermal pretreatment remained unchanged and undestroyed (data not shown). The new pretreatment had relatively milder reaction conditions than the conventional acid or alkali pretreatment. Basing on the characteristics of algal microstructure and the effect of hydroxyl radicals, we speculated the mechanism of thermal hydroxyl radical pretreatment. Hydroxyl radical-aided thermal pretreatment first removes alginate, mannitol, carrageenan, and agar in the outer layer of the algal biomass. Thus, the cellulose and hemicelluloses embedded inside the algal biomass become fully exposed. Adding $\mathrm{FeSO}_{4}$ and $\mathrm{H}_{2} \mathrm{O}_{2}$ creates a sufficient amount of $\cdot \mathrm{OH}$. Moreover, the hydroxyl radical-aided thermal pretreatment requires a high temperature to accelerate the motion of hydroxyl radicals. Hydroxyl radicals rupture the algal cell walls by cleaving the intermolecular linkages between cellulose and cellulose, cellulose and hemicelluloses, and hemicelluloses and other components. Subsequently, the structural destruction of algal biomass facilitates cellulose degradation. The new pretreatment for algal biomass will be combined with algal biopolymer extraction to provide a novel method for the comprehensive utilization of algae.

This new pretreatment technology followed and simulated efficient conversion of natural biological way from nature. Simulate and reproduce the natural pretreatment process will help us profoundly understand the biomass biodegradation. The hydroxyl radical-aided thermal pretreatment selectively destruct algal cell walls and maximize the retention of cellulose and hemicellulose contents of algal biomass. The new pretreatment 
fundamentally solve the disadvantages of traditional pretreatment such as too strong reaction condition, low carbohydrate recovery, multi-inhibitors, and high-energy consumption. This new pretreatment may provide new insights into the low-cost and high-efficient transformation of algal biomass.

\section{Conclusion}

Hydroxyl radical-aided thermal pretreatment was used as a novel method to disrupt the hydrogen bonds and cellulose crystallinity in algal biomass, which is beneficial to conversion of the carbohydrates in the algal cell wall into simple sugars by enzymolysis process. Overall, this method increased the amount of glucose released from the algal biomass. This method was proven suitable for the eight types of biomass. The new pretreatment requires low concentration of chemical solvents and milder temperature conditions, which can prevent the toxic and corrosive effects that typically result from conventional pretreatments. Moreover, the new method presents advantages over other pretreatment methods, including higher carbohydrate recovery, no inhibitor production, and lowerenergy consumption. The new pretreatment development mimicking natural system could be useful for biochemical conversion of algal biomass to fuels and chemicals.

\section{Methods and materials}

\section{Algal biomass}

Macrocystis pyrifera, U. prolifera, G. amansii, and P. umbilicalis were purchased from QingDao MingYue Seaweed Group (Qingdao, China). C. sorokiniana (UTEX 1602) was obtained from the Culture Collection of Alga at the University of Texas (Austin, TX, USA). H. pluvialis was obtained from the Washington State University (Washington, USA). S. quadricanda and C. hedleyi were collected from Bohai Bay, China [23]. All samples were dried at $65^{\circ} \mathrm{C}$ for $24 \mathrm{~h}$. The macroalgae were additionally milled to an average size of 80 mesh $(0.22 \mathrm{~mm})$ using a standard sieve. The screened samples were directly used in pretreatment studies.

\section{Hydroxyl radical-aided thermal pretreatment technologies}

The pretreatment was conducted in $100 \mathrm{~mL}$ Erlenmeyer flasks with a total working volume of $50 \mathrm{~mL}$. The reaction reactor was loaded with $2.5 \mathrm{~g}$ of dried algal biomass. The algal biomass was treated with optimal concentrations of $\mathrm{H}_{2} \mathrm{O}_{2}$ and $\mathrm{FeSO}_{4}$, and then stirred for 3-5 s. The algal biomass medium was thermally pretreated at different temperatures from 80 to $120^{\circ} \mathrm{C}$. The thermal pretreatment can enhance the functions of hydroxyl radicals. The reaction mixture was directly used for subsequent hydrolysis experiments.

\section{Experimental design}

CCD was used to optimize the process parameters of the new algal pretreatment for glucose production. The parameters optimized in the hydroxyl radical-aided thermal pretreatment include reaction time, temperature, and $\mathrm{H}_{2} \mathrm{O}_{2}$ concentration (Table 4). The process variables in preliminary experiments were estimated through single factor experiments. Triplicate runs were conducted for each combination: $\mathrm{H}_{2} \mathrm{O}_{2}$ concentration (3.5$7.1 \mathrm{mM})$, temperatures $\left(80-120^{\circ} \mathrm{C}\right)$, and reaction times (15-45 $\mathrm{min})$. The results from the experimental work were statistically analyzed using "Statistica 6.0" (StatSoft Inc., 2001) and "Minitab" (Minitab Inc.). The effect of each parameter was evaluated to determine the optimal parameters at which the highest glucose yield can be obtained.

\section{Analysis methods \\ Analysis of algal biomass composition}

The carbohydrate in algal biomass was quantitatively analyzed according to the NREL Laboratory Analytical Procedures [28] for biomass using a two-step acid method [24]. Approximately $1 \mathrm{~g}$ (dry basis) of the samples was dispensed into $200 \mathrm{~mL}$ Erlenmeyer flasks. The samples were treated with $5 \mathrm{~mL}$ of $72 \%(\mathrm{w} / \mathrm{w}) \mathrm{H}_{2} \mathrm{SO}_{4}$ at $30^{\circ} \mathrm{C}$ for $2.5 \mathrm{~h}$ and then stirred every $15 \mathrm{~min}$ with a glass stirring rod. The solutions were diluted with $181.7 \mathrm{~mL}$ of water and then autoclaved at $121{ }^{\circ} \mathrm{C}$ for $1 \mathrm{~h}$. After autoclaving, the serum vials were cooled, and the samples were immediately centrifuged at $10,000 \times g$ for $20 \mathrm{~min}$ to remove solid particles. The supernatant was passed through a $0.22-\mu \mathrm{m}$ filter. Glucose and xylose concentrations were determined using high-performance liquid chromatography (HPLC, Shimadzu, Kyoto, Japan) with a refractive index detector (Shimadzu) on an Aminex HPX-87H column (Bio-Rad, Hercules, CA, USA). The flow rate was $0.6 \mathrm{~mL} / \mathrm{min}$ at $60{ }^{\circ} \mathrm{C}$, and the mobile phase was $5 \mathrm{mM} \mathrm{H}_{2} \mathrm{SO}_{4}$. Glucan and xylan concentrations were calculated according to Eqs. (1) and (2), where factors of 0.9 and 0.88 reflect the weight losses in converting glucose to glucan and xylose to xylan, respectively [25].

$$
\begin{aligned}
& \text { Glucan content }(\%) \\
& =\frac{\text { Glucose released from acid hydrolysis }(\mathrm{mg}) \times 0.9}{\text { Samples weight }(\mathrm{mg})} \\
& \quad \times 100 \%
\end{aligned}
$$

Xylan content (\%)

$$
\begin{aligned}
= & \frac{\text { Xylose released from acid hydrolysis }(\mathrm{mg}) \times 0.88}{\text { Samples weight }(\mathrm{mg})} \\
& \times 100 \%
\end{aligned}
$$




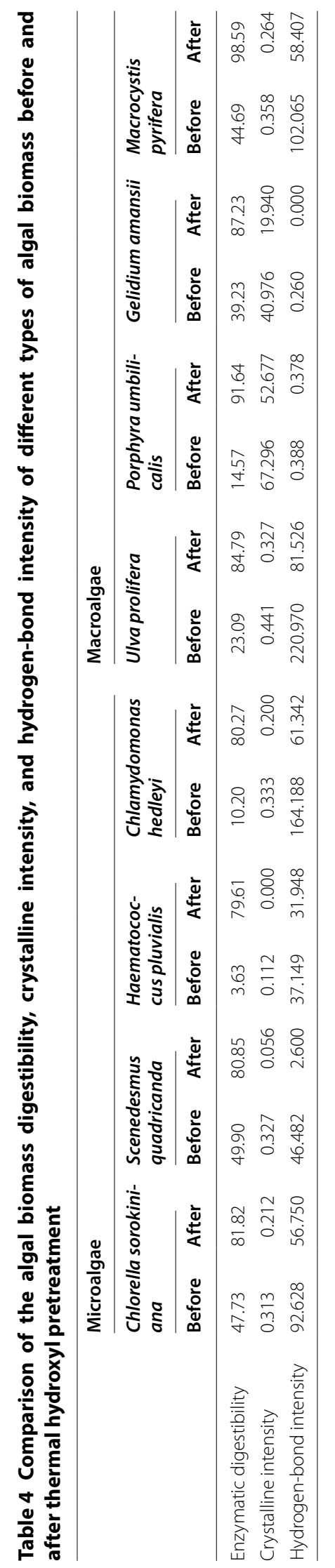


Moisture content was measured by drying the samples at $105{ }^{\circ} \mathrm{C}$ in an oven until constant weight [26]. The content of intracellular proteins was determined using the Bradford method [29, 27]. The cells were disrupted through sonication in phosphate-buffered saline, and the supernatant was colored by mixing with the Bradford reagent (Sigma Chemical Co., St. Louis, MO, USA). Optical density was determined at $595 \mathrm{~nm}$. Ash content was determined by heating the samples at $550{ }^{\circ} \mathrm{C}$ for $1 \mathrm{~h}$. Crude lipid was extracted using the Soxhlet method with petroleum ether as the solvent [14].

\section{Analysis of inhibitors}

Furfural and 5-HMF were analyzed using HPLC (Shimadzu LC-20A, Kyoto, Japan) with a UV detector at a wavelength of $215 \mathrm{~nm}$. The samples were diluted and passed through a $0.22 \mu \mathrm{m}$ filter prior to analysis. 5-HMF and furfural were separated on an Aminex HPX-87H column (Bio-rad) at $35{ }^{\circ} \mathrm{C}$ using $5 \mathrm{mM} \mathrm{H}_{2} \mathrm{SO}_{4}$ as the eluent at $35^{\circ} \mathrm{C}$ with a flow rate of $0.5 \mathrm{~mL} / \mathrm{min}$ [28].

\section{Analysis of hydrolyzates}

The concentration of sugars in the liquid fraction of the enzymatic hydrolyzate was quantified using HPLC (Shimadzu, Kyoto, Japan) with a refractive index detector (Shimadzu). The samples were separated on an Aminex HPX-87H column (Bio-Rad, Hercules, CA, USA) using $5 \mathrm{mM} \mathrm{H}_{2} \mathrm{SO}_{4}$ as the mobile phase at $60{ }^{\circ} \mathrm{C}$ with a flow rate of $0.6 \mathrm{~mL} / \mathrm{min}$.

$$
\begin{aligned}
& \text { Conversion of cellulose }(\%) \\
& =\frac{\text { Glucose released from enzyme hydrolysis }(\mathrm{mg}) \times 0.9}{\text { Samples weight }(\mathrm{mg}) \times \text { Glucan content }(\%)} \\
& \quad \times 100 \%
\end{aligned}
$$

\section{FTIR spectroscopy and XRD analysis}

The samples were dried at $-20{ }^{\circ} \mathrm{C}$ for $24 \mathrm{~h}$ using a vacuum dryer (FD-IC-50, Beijing). IR spectra were determined using an FTIR 710 IR spectrophotometer (Nicolet, Madison, WI). A specific amount of the powder was dispersed in spectroscopic-grade $\mathrm{KBr}$ and then pressed into disks using ten tons of pressure for $1 \mathrm{~min}$. A total of 100 scans with a $2 \mathrm{~cm}^{-1}$ resolution were signal averaged and then stored. The wave number was scanned within the range of $4000-400 \mathrm{~cm}^{-1}$. The ratio of absorbance at $4000-2995 \mathrm{~cm}^{-1}$ to those at $1337 \mathrm{~cm}^{-1}$ of $\mathrm{C}-\mathrm{OH}$ inplane stretching was introduced as an empirical criterion of HBI [29].

$$
\mathrm{HBI}=\frac{\text { Absorbance }\left(4000-2995 \mathrm{~cm}^{-1}\right)}{\text { Absorbance }\left(1337 \mathrm{~cm}^{-1}\right)}
$$

The overall crystallinity of the macroalgae subjected to the new pretreatment was examined through XRD on a
Bruker D8 Advance Diffractometer with $\mathrm{Cu} \mathrm{K} \alpha$ radiation $(\lambda=0.1541 \mathrm{~nm})$ at $30 \mathrm{kV}$ and $30 \mathrm{~mA}$ [24]. The samples were scanned, and the intensity was recorded in the $2 \theta$ range of $10^{\circ}-80^{\circ}$.

To compare the intensity differences and determine the pretreatment effects, we calculated the CrI of the cotton fiber by referring to the diffraction intensities of the crystalline area and amorphous region using the following equation:

$$
\mathrm{CrI}=\frac{I_{002}-I_{\mathrm{am}}}{I_{002}}
$$

where $I_{002}$ is the intensity of the crystalline area of the plane at $2 \theta=22.40$, and $I_{\mathrm{am}}$ is the intensity of the amorphous region at $2 \theta=18.70 . I_{002}$ refers to both crystalline and amorphous intensities, whereas $I_{\mathrm{am}}$ only represents the background intensity.

\section{Enzymatic hydrolysis of pretreated algal biomass}

The pretreated algal biomass and the control (untreated biomass) were subjected to enzymatic hydrolysis with cellulase at $50{ }^{\circ} \mathrm{C}$ for $72 \mathrm{~h}$ in triplicate. Cellulase from Trichoder mareesei ATCC 26921 was purchased from Sigma-Aldrich Co. Hydrolysis experiments were conducted in $50-\mathrm{mL}$ Erlenmeyer flasks with a total working volume of $20 \mathrm{~mL}$ and a substrate concentration of $5 \%$ (w/v). Enzyme loading was $15 \mathrm{FPU} / \mathrm{g}$ substrate. The reaction mixtures were supplemented with $0.5 \% \mathrm{NaN}_{3}$ to prevent microbial contamination. The samples were removed at regular intervals, and the supernatant was boiled to denature the enzyme and terminate its activity. The supernatant was passed through a $0.22-\mu \mathrm{m}$ filter for glucose content analysis. After hydrolysis, the residues were separated from the liquid by centrifugation, decantation, and filtration. The sugar in the liquid was then analyzed.

\section{Additional file}

Additional file 1: Table S1. Proximate analysis of dried algal biomass before and after hydroxyl radical-aided thermal pretreatment.

\section{Abbreviations}

HPLC: high-performance liquid chromatography; DM: dry matter; HMF: hydroxymethylfurfural; FTIR: fourier transform infrared spectroscopy; XRD: $X$-ray diffraction; HBI: hydrogen-bond intensity; CCD: central composite design; Crl: crystallinity intensity; $\cdot \mathrm{OH}$ : hydroxyl radicals.

\section{Authors' contributions}

LG planned and carried out the experimental work on hydroxyl radical-aided thermal pretreatment and enzymatic hydrolysis of pretreated algal biomass, collected the data, and drafted the manuscript. DML participated in the interpretation of the data and helped to revise the manuscript. FG participated in the design of central composite design of pretreatment and helped to revise the manuscript. ZYL and YYH carried out the experimental work on structural changes analysis of algal biomass after pretreatment and helped to draft the 
manuscript. SLC participated in the design of the study and helped to revise the manuscript. DYZ provided the original idea, performed the statistical analysis, and helped to revise the manuscript. All authors read and approved the final manuscript submitted to Biotechnol Biofuels, and affirm it is the original work of the authors. All authors read and approved the final manuscript.

\section{Acknowledgements}

This work was supported by the Chinese National Natural Science Foundation for the Youth (21406260), and the Hi-Tech Research and Development Program (863) of China (2014AA021906).

\section{Competing interests}

The authors declare that they have no competing interests.

Received: 14 April 2015 Accepted: 9 November 2015

Published online: 26 November 2015

\section{References}

1. Roesijadi G, Jones SB, Snowden-Swan LJ, Zhu Y. Macroalgae as a biomass feedstock: a preliminary analysis. US DOE, PNNL-19944. 2010.

2. Jones CS, Mayfield SP. Algae biofuels:versatility for the future of bioenergy. Current opinion in biotechnology. Curr Opin Biotechnol. 2012:23(3):1-6.

3. Wegeberg S, Felby C. Algae biomass for bioenergy in Denmark: biologi$\mathrm{cal} /$ technical challenges and opportunities. University of Copenhagen. 2010. http://www.bio4bio.dk/ /media/Bio4bio/publications/Review_of_ algae_biomass_for_energy_SW_CF_April2010.ashx

4. Harun R, Danquah MK. Influence of acid pre-treatment on microalgal biomass for bioethanol production. Process Biochem. 2011;46:304-9.

5. Yazdani P, Keikhosro K, Taherzadeh MJ. Improvement of enzymatic hydrolysis of a marine macro-alga by dilute acid hydrolysis pretreatment. World Renew Energy Congr. 2011;5:8-13.

6. Lee JY, Li P, Lee J, Ryu HJ, Oh KK. Ethanol production from Saccharina japonica using an extremely low acid pretreatment followed by simultaneous saccharification and fermentation. Bioresour Technol. 2013;127:119-25.

7. Schultz-Jensen N, Thygesen A, Leipold F, Thomsen ST, Roslander C, Lilholt $\mathrm{H}$, et al. Pretreatment of the macroalgae Chaetomoroha linum for the production of bioethanol-comparison of five pretreatment technologies. Bioresour Technol. 2013;140:36-42.

8. Ke J, Laskar DD, Singh D, Chen SL. In situ lignocellulosic unlocking mechanism for carbohydrate hydrolysis in termites: crucial lignin modification. Biotechnol Biofuel. 2011:4:17.

9. Lodha B, Chaudhari S. Optimization of Fenton-biological treatment scheme for the treatment of aqueous dye solutions. J Hazard Mater. 2007;148:459-66.

10. Gould JM. Alkaline peroxide delignification of agricultural residues to enhance enzymatic saccharification. Biotechnol Bioeng. 1984;26:46-52.
11. Ross AB, Jones JM, Kubacki ML, Bridgeman T. Classification of macroalgae as fuel and its thermochemical behaviour. Bioresour Technol. 2008;99:6494-504.

12. Andrade LR, Salgado LT, Farina M, Pereira MS, Mourão P, Filho G. Ultrastructure of acidic polysaccharides from the cell walls of brown algae. J Struct Biol. 2004;145:216-25.

13. Whyte J, Englar JR. The agar component of the red seaweed. Phytochemistry. 1981;20:237-40.

14. Borines MG, Leon RD, Cuello JL. Bioethanol production from the macroalgae Sargassum spp. Bioresour Technol. 2013;138:22-9.

15. Gao F, Gao L, Zhang DY, Ye NH, Chen SL, Li DM. Enhanced hydrolysis of Macrocystis pyrifera by integrated hydroxyl radicals and hot water pretreatment. Bioresour Technol. 2015;179:490-6.

16. Grohmann K, Torget R, Himmel M. Dilute acid pretreatment of biomass at high solids concentrations. Biotechnol Bioeng Symp. 1986;17:135-51.

17. Harun R, Jason WSY, Cherrington T, Danquah MK. Microalgal biomass as a cellulosic fermentation feedstock for, bioethanol production. Appl Energy. 2011;88:3464-7.

18. Datar R, Huang J, Maness PC, Mohagheghi A, Czernik S, Chornet E. Hydrogen production from the fermentation of corn stover biomass pretreated with a steam-explosion process. Int J Hydrog Energy. 2007;32:932-9.

19. Jung KW, Kim DH, Shin HS. Fermentative hydrogen production from laminaria japonica and optimization of thermal pretreatment conditions. Bioresour Technol. 2011;102:2745-50.

20. Yu CT, Chen WH, Men LC, Hwang WS. Microscopic structure fewtures changes of rice straw treated by boiled acid solution. Ind Crops Prod. 2009;29(2-3):308-15.

21. Davis TA, Volesky B, Mucci A. A review of the biochemistry of heavy metal biosorption by brown algae. Water Res. 2003;37:4311-30.

22. Percival E. The polysaccharides of green, red and brown seaweeds: their basic structure, biosynthesis and function. Br Phycol J. 1979;14:103-17.

23. Jung KW, Kim DH, Shin HS. Fermentative hydrogen production from Laminaria japonica and optimization of thermal pretreatment conditions. Bioresour Technol. 2011;102:2745-50.

24. Liu ZY, Liu CF, Hou YY, Chen SL, Xiao DG, Zhang JK, Chen FJ. Isolation and characterization of a marine microalga for biofuel production with astaxanthin as a co-product. Energies. 2013;6:2759-72.

25. Sluiter BHA, Ruiz R, Scarlata C, Sluiter J, Templeton D, Crocker D. Determination of structural carbohydrates and lignin in biomass. NREL/TP-51042618. 2008.

26. Shi SL, He FW. Analysis and measurement of pulp and paper (in Chinese). Beijing: Chinese Light Industry Press; 2008.

27. NREL. Standard method for determination of total solids in biomass. Biomass Progr. 2006. http://www.afdc.doe.gov/pdfs/4684.pdf.

28. Bradford MM. A rapid and sensitive method for the quantitation of microgram quantities of protein utilizing the principle of protein-dye binding. Anal Biochem. 1976;72:248-54.

29. Yao L, Yue J, Zhao J, Dong JQ, Li XZ, Qu YB. Application of acidic wastewater from monosodium glutamate process in pretreatment and cellulase production for bioconversion of corn stover-feasibility evaluation. Bioresour Technol. 2010;101:8755-61.

\section{Submit your next manuscript to BioMed Central and take full advantage of:}

- Convenient online submission

- Thorough peer review

- No space constraints or color figure charges

- Immediate publication on acceptance

- Inclusion in PubMed, CAS, Scopus and Google Scholar

- Research which is freely available for redistribution

Submit your manuscript at

www.biomedcentral.com/submit
C Biomed Central 